\title{
Analisis Implementasi Kebijakan Kawasan Tanpa Rokok Berdasarkan Perda Nomor 5 Tahun 2016 Di Dinas Kesehatan Kabupaten Indragiri Hilir
}

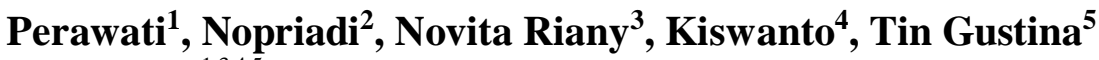 \\ 1,3,4,5 STIKes Hang Tuah Pekanbaru dan Pekanbaru \\ ${ }^{2}$ Universitas Riau dan Pekanbaru \\ Correspondence email: verawati837@yahoo.co.id
}

\begin{abstract}
Abstrak. Program Kawasan Tanpa Rokok (KTR) merupakan salah satu kebjakan yang diambil oleh pemerintah untuk mengendalikan efek negatif yang ditimbulkan dari kebiasaan merokok dimasyarakat. Tujuan penelitian ini adalah menganalisis implementasi kebijakan KTR berdasarkan Perda No. 5 Tahun 2016 di Dinkes Kabupaten Indragiri Hilir tahun 2020. Penelitian ini menggunakan pendekatan kualitatif dengan desain fenomenologi. Teknik pengumpulan data pada penelitian ini berupa wawancara mendalam (indepth interview), observasi dan penelusuran dokumen. Jumlah informan pada penelitian adalah 8 orang. Hasil penelitian didapatkan bahwa implementasi Perda KTR dikawasan Dinkes Kabupaten Indragiri Hilir belum terlaksana dengan efektif. Hal ini disebabkan karena beberapa faktor, yaitu kurangnya sosialisasi, minimnya ketersediaan sarana prasarana, belu m ada struktur organisasi, belum ada komite pengawas, dan belum ada kebijakan terhadap sanksi pelanggaran. Disarankan kepada Dinas Kesehatan agar melengkapi fasilitas sarana prasarana, memberikan sosialisasi, menyusun struktur organisasi, membentuk komite pengawas, dan menegakkan sanksi pelangaran. Direkomendasikan juga kepada Dinas Kesehatan membuat turunanturunan dari perda tersebut seperti Peraturan Bupati, petunjuk pelaksana, dan petunjuk teknis sehingga ada kekuatan hukum.
\end{abstract}

Kata kunci: Implementasi KTR; Rokok; Dinas Kesehatan

\begin{abstract}
The No Smoking Area Program (KTR) is one of the policies taken by the government to control the negative effects of smoking in the community. The purpose of this study was to analyze the implementation of the KTR policy based on Perda No. 5 of 2016 at the Indragiri Hilir District Health Office in 2020. This research uses a qualitative approach with a phenomenological design. Data collection techniques in this study were in-depth interviews, observation and document searches. The number of informants in the study was 8 people. The results showed that the implementation of the Regional Regulation on KTR in the area of Indragiri Hilir District Health Office has not been implemented effectively. This is due to several factors, namely lack of socialization, lack of availability of infrastructure, no organizational structure, no supervisory committee, and no policy against sanctions for violations. It is recommended that the Health Office complete the facilities and infrastructure, provide outreach, compile an organizational structure, form a supervisory committee, and enforce the sanctions for infringement. It is also recommended that the Health Office prepare derivatives of these perda, such as a Regent Regulation, implementing guidelines, and technical guidelines so that there is legal power.
\end{abstract}

Keywords: Implementation of KTR; Cigarettes; Health Office

\section{PENDAHULUAN}

Masalah rokok saat ini menjadi perhatian serius berbagai negara di dunia karena dampak yang ditimbulkan dari asap rokok sangat berbahaya bagi kesehatan. Selain itu masalah kebiasaan merokok di tempat umum sangat mengganggu kenyamanan dan mempengaruhi kesehatan bagi orang yang ada disekitarnya. Hal ini disebabkan karena rokok yang terbakar menghasilkan asap sampingan sebanyak 2 kali lipat lebih banyak dari pada asap utama serta mengandung kadar bahan-bahan berbahaya yang juga lebih tinggi ( Riskesdas, 2018).

Berdasarkan data terbaru dari The Tobacco Atlas tahun 2015, Indonesia menduduki peringkat pertama di dunia untuk jumlah perokok pria di atas usia 15 tahun. Hasil riset kesehatan dasar tahun 2013 menyebutkan bahwa penduduk Indonesia yang berumur 10-14 tahun sudah menjadi perokok aktif. Perokok usia dini mengalami peningkatan 100\%, pada tahun 1995 sebesar
$8,9 \%$ dan angka tersebut terus meningkat pada tahun 2013 menjadi 18\% (Riskesdas, 2013).

Rata-rata batang rokok yang dihisap per hari penduduk Indonesia pada umur $\geq 10$ tahun adalah 12,3 batang (setara satu bungkus). Rerata batang rokok yang dihisap perhari pada penduduk Propinsi Riau tergolong tinggi yaitu 16 batang. Proporsi perokok di Riau yaitu $24,2 \%$, dengan proporsi perokok setiap hari pada usia 15-19 tahun 8,5\% dan perokok kadang-kadang sebesar $5,8 \%$. Kota Pekanbaru memiliki proporsi perokok dengan kebiasaan merokok setiap hari ( $\geq 10$ tahun) berjumlah 19,4\% dan perokok kadang-kadang 5,1\% (Kemenkes RI, 2013).

WHO merekomendasikan bahwa lingkungan bebas asap rokok $100 \%$ adalah satu satu cara yang efektif untuk mengurang paparan asap rokok orang lain di dalam ruangan (TCSC, 2012). Berdasarkan studi pendahuluan yang dilakukan peneliti pada bulan April tahun 2020 didapatkan informasi bahwa pemerintah daerah Kabupaten Indragiri Hilir telah mengeluarkan 
Peraturan Daerah (PERDA) Kabupaten Indragiri Hilir Nomor 5 tahun 2016 tentang Kawasan Tanpa Rokok (KTR). PERDA tersebut dikeluarkan berdasarkan Undang-Undang Republik Indonesia Nomor 36 Tahun 2009 yang mewajibkan kepada Pemerintah Daerah untuk menetapkan Kawasan Tanpa Rokok (KTR) di wilayah masing-masing. Namun, hasil observasi yang dilakukan peneliti, masih didapatkannya pengunjung dan petugas di Dinas Kesehatan Kabupaten Indragiri Hilir yang merokok di wilayah kawasan tanpa rokok.

Berdasarkan hasil studi pendahuluan dan fenomena diatas, peneliti tertarik untuk melakukan penelitian tentang analisis implementasi peraturan daerah Kabupaten Indragiri Hilir Nomor 5 tahun 2016 tentang kawasan tanpa rokok di Dinas Kesehatan Kabupaten Indragiri Hilir. Penelitian ini bertujuan untuk menganalisis implementasi peraturan daerah Kabupaten Indragiri Hilir Nomor 5 tahun 2016 tentang kawasan tanpa rokok di Dinas Kesehatan Kabupaten Indragiri Hilir tahun 2020.

\section{METODE}

Penelitian ini merupakan penelitian kualitatif yang bersifat deskriptif eksploratif dengan menggunakan desain penelitian fenomonologi dalam mendapatkan informasi. Penunjukan informan menggunakan teknik purposive sampling, yaitu berdasarkan pertimbangan tertentu yang dipandang dapat memberikan data secara maksimal serta yang memiliki pengetahuan berkaitan dengan objek penelitian. Informan pada penelitian ini terdiri dari informan utama dan informan pendukung. Informan utama pada penelitian ini adalah pegawai dinas kesehatan Kabupaten Indragiri Hilir dan security dinas kesehatan, sedangkan informan pendukung pada penelitian ini adalah Kepala Dinas Kesehatan Kabupaten Indragiri Hilir, Kepala Seksi Promosi Kesehatan, pengunjung Dinkes Kabupaten Indragiri Hilir, dan stakeholder yaitu Satpol PP. Teknik pengumpulan data pada penelitian ini melalui wawancara mendalam (indepth interview), observasi dan penelusuran dokumen. Informasi yang diperoleh akan dilakukan triangulasi data yang bertujuan untuk membandingkan kebenaran informasi-informasi yang diperoleh dari para pegawai Dinas Kesehatan Kabuapten Indragiri Hilir dengan pengujung atau tamu yang berkunjung di Dinas Kesehatan Kabupaten Indragiri Hilir. Teknik analisis data yang dilakukan mencakup reduksi data (data reduction), penyajian data (data display) dan kesimpulan atau verifikasi (conclusion).

\section{HASIL DAN PEMBAHASAN Karakteristik Informan}

Berdasarakan hasil analisis pada Tabel 1 diatas diketahui bahwa umur informan yang berada pada kelompok umur masa dewasa akhir (36-45 tahun) dan masa lansia awal (46-55 tahun) sama banyak, yaitu $37.5 \%$ sedangkan kelompok umur dewasa awal (26-35 tahun) sebanyak $25 \%$. Jenis kelamin informan terbanyak adalah laki-laki dengan persentase $62.5 \%$, pendidikan terakhir informan terbanyak S1 dengan persentase $50 \%$ dan jabatan informan dari penelitian ini didapatkan dari berbagai jenis jabatan dengan persentase masing-masing jabatan sebesar $10 \%$.

Tabel 1. Karakteristik Informan

\begin{tabular}{lccccc}
\hline No & Umur & Jenis Kelamin & Pendidikan & Pekerjaan/Jabatan & Kode \\
\hline 1. & 37 & L & S1 & Staf Promkes & Inf 1 \\
2. & 55 & L & S1 & Staf Perencanaan & Inf 2 \\
3. & 42 & P & S1 & Staf Kepegawaian & Inf 3 \\
4. & 30 & L & SMA & Security & Inf 4 \\
5. & 52 & P & S2 & Kepala Dinkes & Inf 5 \\
6. & 40 & P & S2 & Kasi Promkes & Inf 6 \\
7. & 49 & L & SMA & Pengunjung & Inf 7 \\
8. & 36 & L & S1 & Pegawai Satpo PP & Inf 8 \\
\hline
\end{tabular}

Implementasi Peraturan Daerah Kabupaten Indragiri Hilir Nomor 5 tahun 2016 tentang kawasan tanpa rokok

Faktor Sumber Daya

Hasil yang diperoleh terkait faktor sumber daya pada implementasi kebijakan Peraturan Daerah Kabupaten Indragiri Hilir Nomor 5 tahun 2016 tentang kawasan tanpa rokok diperoleh informasi bahwa sasaran pelaksanaan kebijakan KTR saat ini adalah pegawai dan pengujung Dinkes Kabupaten Inhil sendiri, seperti kutipan berikut:
"Banyak unsur ordinasi lain mungkin diluar kewenangan Dinkes, ada kepolisian, dan juga/kesyahbandaran dll, itu kami tidak bisa memberikan semacam arahan secara intensif, cuma himbauan, yang bisa kita arahkan adalah pegawai Dinkes Tembilahan sendiri" (Inf 5)

"Seтua pegawai dinas kesehatan inilah..dan pengunjung dinas kesehatan" (Inf1-inf 4,Inf 6-Inf 8)

Informasi tentang Pedoman dalam melakukan pelaksanaan kebijakan KTR diperoleh dari informan Nomor 5 dan 6 bahwa Pedoman berupa SOP belum ada, 
Perawati, Nopriadi, Novita Riany, Kiswanto dan Tin Gustina, Analisis Implementasi Kebijakan Kawasan Tanpa Rokok Berdasarkan Perda Nomor 5 Tahun 2016 Di Dinas Kesehatan Kabupaten Indragiri Hilir

yang ada hanya Perda Kabupaten Indragiri Hilir Nomor 5 Tentang KTR, seperti kutipan berikut:

"Untuk pedomannya berdasarkan perda nomor 5 tahun 2016, sekarang sedang disusun perbup untuk melengkapi perda tersebut". (Inf 5)

"Belum, SOP belum ada, hanya berdasarkan Perda Kabupaten Indragiri Hilir Nomor 5 tahun 2016 tentang KTR”. (Inf 6)

Setelah dilakukan penelusuran dokumen mengenai pedoman dalam melakukan pelaksanaan kebijakan didapatkan bahwa memang belum memiliki SOP sebagai pedoman dalam melaksanakan kebijakan, hanya berdasarkan Perda Kabupaten Indragiri Hilir Nomor 5 Tahun 2016 tentang KTR.

Informasi terkait sarana dan prasarana implementasi kebijakan KTR dari seluruh informan diperoleh bahwa informan mengetahui dan melihat adanya spanduk Kawasan Tanpa Rokok di Dinkes Kabupaten Indragiri Hilir, seperti kutipan berikut:

"Rambu larangan merokok ada tapi masih minim. Kalo bisa ditingkatkan lagi seperti dengan hal-hal yang kreatif" (Inf 1-Inf 8).

Berdasarkan observasi yang dilakukan peneliti juga melihat sarana berupa poster dan spanduk larangan merokok pada dinding, dan belum ada rambu-rambu batasan merokok di kawasan Dinkes Kabupaten Inhil. Hal ini dapat dilihat pada gambar 1 dan 2 dibawah ini.

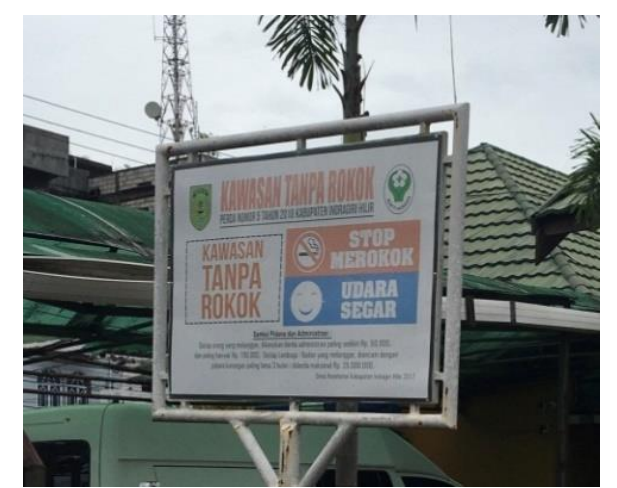

Gambar 1. Spanduk Kawasan Tanpa Rokok

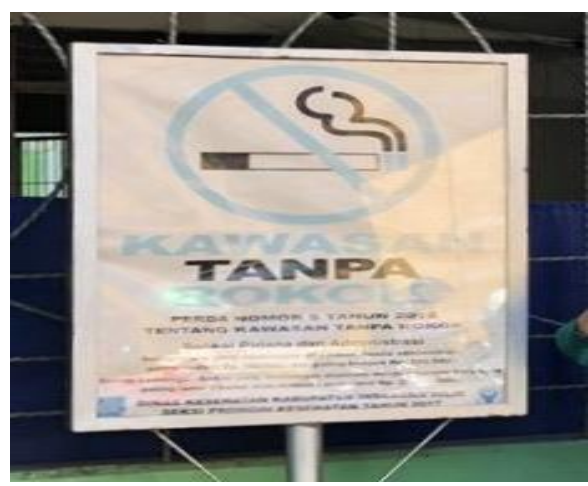

Gambar 2. Poster Larangan Merokok
Berdasarkan hasil wawancara sebagian besar informan menyatakan tempat khusus untuk merokok di luar ruangan belum ada, seperti kutipan berikut:

"Tempat untuk merokok di ruangan terbuka dan belum ada ruang khusus". (Inf 2, Inf 3, Inf 4,Inf 6, Inf 7, $\operatorname{Inf} 8$, )

"Kalau prasarana seperti ruangan merokok sebaiknya emang tidak harus ada disini". (Inf 1)

* "Yang jelas tidak dalam lingkungan Dinas Kesehatan". (Inf 5)

Berdasarkan observasi yang dilakukan peneliti juga melihat pegawai dan pengunjung merokok di kawasan Dinkes Kabupaten Inhil. Hal ini dibuktikan dengan masih ditemukan adanya puntung rokok dan asbak dilingkungan sekitar, sebagaimana gambar 3 dan 4 berikut.

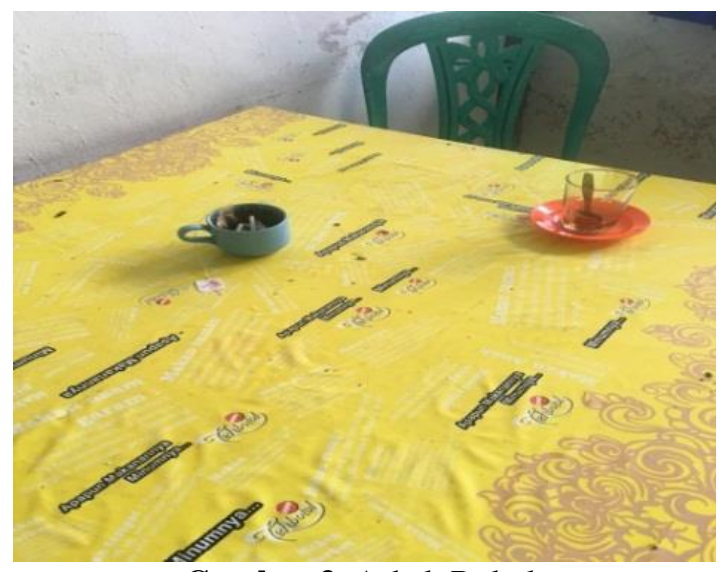

Gambar 3. Asbak Rokok

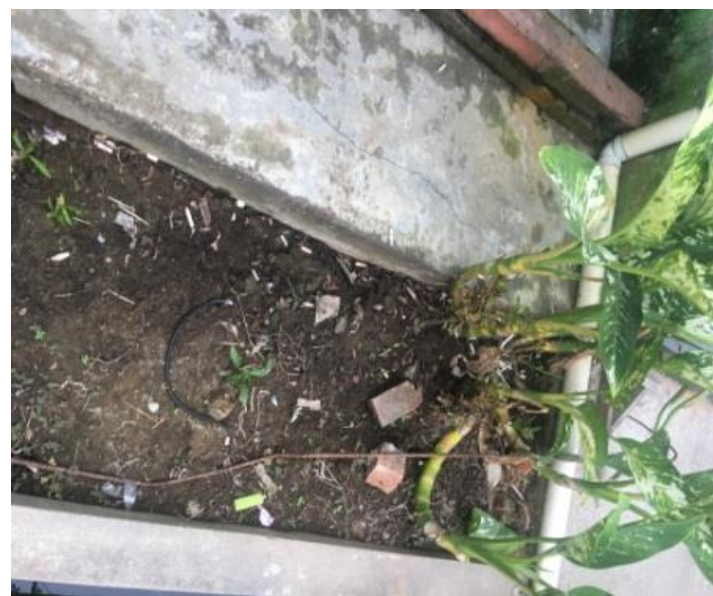

Gambar 4. Puntung Rokok

Hasil triangulasi data informasi SDM dan sarana prasarana pelaksanaan kebijakan KTR berdasarkan Perda nomor 5 tahun 2016 diperoleh hasil bahwa pelaksanaan kebijakan hanya berdasarkan Perda nomor 5 tahun 2016 tentang KTR dan masih minimnya fasilitas sarana dan prasarana pendukung dalam pelaksanaan KTR. 
Perawati, Nopriadi, Novita Riany, Kiswanto dan Tin Gustina, Analisis Implementasi Kebijakan Kawasan Tanpa Rokok Berdasarkan Perda Nomor 5 Tahun 2016 Di Dinas Kesehatan Kabupaten Indragiri Hilir

\section{Faktor Komunikasi}

Pernyataan informan tentang faktor Komunikasi terhadap implementasi kebijakan Kawasan Tanpa Rokok berdasarkan Perda No. 5 Tahun 2016 di Dinkes Kabupaten Inhil tahun 2020 didapatkan hasil bahwa hampir semua informan menyatakan sudah mendapatkan informasi mengenai adanya Kawasan Tanpa Rokok di Kawasan Dinkes Kabupaten Inhil namun belum sepenuhnya memahami isi Perda tersebut dan masih ada informan yang belum pernah mendapatkan sosialisasi tentang KTR. ditandai dengan hasil wawancara mendalam sebagai berikut:

"Tau, saya melihat itu bagus, berarti ada keinginan Pemda untuk menciptakan tempat-tempat yang ramah untuk anak untuk lingkungan" (Inf 1-Inf 3,Inf 5,Inf 6,Inf 8).

"hanya sebatas tau saja dilihat dari spanduk tapi kalua perda kurang memahami". (Inf 2,Inf 4)

Akan tetapi terdapat 1 orang informan yaitu pengunjung sama sekali belum mengetahui bahwa adanya Kawasan Tanpa Rokok di Kawasan Dinkes Kabupaten Inhil, di tandai dengan jawaban informan sebagai berikut:

"Saya tidak tahu Perda tersebut dan juga tidak pernah mendapatkan sosialisasi dari pihak manapun". (Inf 7)

Hasil lainnya yang didapatkan dari informasi terkait faktor komunikasi adalah seluruh informan cenderung menyatakan belum pernah mendapatkan sosialisasi secara langsung mengenai Peraturan Daerah Kabupaten Indragiri Hilir Nomor 5 Tahun 2016 tentang KTR di kawasan Dinas Kesehatan Kabupaten Indragiri Hilir. Pernyataan informan tersebut dapat dilihat pada hasil wawancara berikut ini:

"Selama ini belum, padahal penting adanya sosialisas secara langsung, sosialisasinya hanya sebatas spanduk dan rambu larangan merokok". (Inf $2, \operatorname{Inf} 4, \operatorname{Inf} 6, \operatorname{Inf} 7$ )

Bentuk sosialisasi yang dilakukan di kawasan Dinkes Kabupaten Inhil hanya berupa penandatanganan komitmen bersama antar lintas sektor bentuk implementasinya dengan membuat rambu-rambu maupun spanduk mengenai Kawasan Tanpa Rokok. Pernyataan informan terkait pernyataan tersebut dapat dilihat pada hasil wawancara berikut ini:

"Sudah ada sosialisasi mengenai KTR, dan itu diimplementasikan dalam bentuk komitmen bersama kemarin, juga dalam bentuk spanduk yang kita pasang khusus ditempat yang bisa dilihat oleh masyarakat yang berkunjung". (Inf 1,Inf 3,Inf 5,Inf 8).
* "Pernah melakukan pertemuan khusus dengan instansi yang terlibat dalam pembuatan Perda tersebut".

Selanjutnya hasil penelusuran dokumen di dapatkan ada dilakukan penandatanganan komitmen bersama di lingkungan Dinas Kesehatan Kabupaten Indragiri Hilir. Hal ini di buktikan dengan gambar 5 berikut:

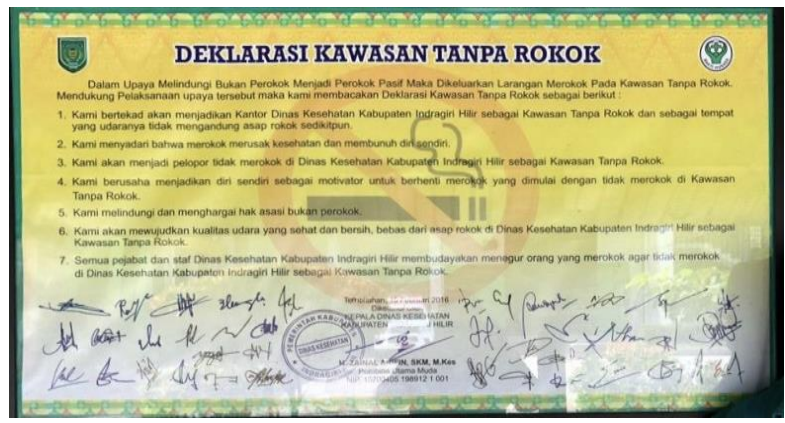

Gambar 5. Penandatanganan Komitmen Bersama

Hasil triangulasi bentuk komunikasi pelaksanaan keijakan kawasan tanpa rokok berdasarkan Perda nomor 5 tahun 2016 di kawasan Dinas Kesehatan Kabupaten Indragiri Hilir diperoleh hasil komunikasi yang dilakukan kurang berjalan dengan baik dari pihak pembuat kebijakan kepada pelaksana kebijakan sehingga sosialisasi tidak berjalan maksimal.

\section{Faktor Disposisi}

Hasil yang diperoleh terkait faktor disposisi pada implementasi kebijakan Peraturan Daerah Kabupaten Indragiri Hilir Nomor 5 tahun 2016 tentang kawasan tanpa rokok diperoleh informasi bahwa seluruh Informan menyatakan setuju dan mendukung penuh terhadap pelaksanaan Perda Kabupaten Indragiri Hilir Nomor 5 Tahun 2016 tentang KTR di Kawasan Dinkes Kabupaten Inhil. Meskipun pelaksanaannya sampai saat ini belum berjalan secara maksimal dan ada informan yang berpendapat bahwa kebijakan KTR akan menciptakan masyarakat sehat dan menjauhkan bahaya asap rokok dari yang bukan perokok. Pernyataan informan tersebut dapat dilihat sebagai berikut ini.

"akan kita tinjau kembali perda ini karena kerugian bukan saja dari mereka akan tetapi juga sangat merugikan orang disekitarnya".( Inf 5)

"Saya mendukung "adanya penerapan KTR di Dinkes Tembilahan, karena masih ada pegawai yang sembarang merokok bukan pada tempat yang sudah ditentukan". (Inf 1- $\operatorname{Inf} 8)$

Penerapan Kawasan Tanpa Rokok di lingkungan Dinas Kesehatan Kabupaten Indragiri Hilir Perlu adanya kejelasan tentang tugas dan tanggung jawab dari penerapan kebijakan tersebut baik pelaksana monitoring 
dan penegakan terhadap sanksi pelanggaran. Berikut pemaparan dari hasil wawancara terhadap beberapa informan:

\begin{abstract}
"Penerapan KTR di Dinkes masih banyak yang perlu diperbaiki, bagi saya jika kebijakan tersebut ingin diterapkan perlu dikaji ulang sebetulnya siapa sih penegak kebijakan tersebut dan siapa sih yang harus memberikan sanksi, karena menurut saya, aturan kalau sanksinya tidak bisa ditegakkan efektifitasnya akan kurang". ( Inf 1, Inf 2)

"Penerapan Kawasan Tanpa Rokok di Dinkes Tembilahan belum berjalan maksimal, masih ada saya melihat pegawai dan pengunjung merokok di sini, saya mendukung adanya kebijakan Kawasan Tanpa Rokok disini dan jika saya melihat ada yang merokok saya tegur, hanya saja sanksi pelanggaran tidak ditegakkan". (Inf 3-Inf 8)
\end{abstract}

Berdasarkan observasi yang dilakukan peneliti diperoleh bahwa sanksi yang diberikan hanya sebatas teguran secara lisan.

Hasil triangulasi tentang disposisi atau sikap pada pelaksananaan kebijakan kawasan tanpa rokok berdasarkan Perda nomor 5 tahun 2016 di kawasan Dinas Kesehatan Kabupaten Indragiri Hilir diperoleh hasil belum ada kejelasan tentang tugas dan tanggung jawab dari penerapan kebijakan baik pelaksana monitoring dan penegakan terhadap sanksi pelanggaran meskipun pelaksana kebijakan mendukung adanya KTR di kawasan Dinkes.

\section{Faktor Birokrasi}

Pernyataan Informan tentang Faktor Birokrasi terhadap Implementasi Peraturan Daerah Kabupaten Indragiri Hilir Nomor 5 Tahun 2016 Tentang Kawasan Tanpa Rokok di Kawasan Dinkes Kabupaten Inhil didapatkan hasil sebahagian besar informan menyatakan bahwa belum ada komite pengawasan KTR di Kawasan Dinkes Kabupaten Inhil. Informan lain juga menyatakan pengawasan 1 yang dilakukan Dinkes Kabupaten Inhil belum maksimal, Pernyataan informan tersebut dapat dilihat sebagai berikut ini:

\footnotetext{
"Belum ada komite kelompok kerja, perlu diketahui di lingkungan ini banyak instansi yang terlibat, sinkronisasi antar instansi sangat perlu, dengan pemerintah daerah dan dengan masyarakat, semua harus bersatu padu untuk menegakkan aturan, jelas sanksi hukum terhadap pelanggar siapa yang memberikan sanksi dan apa sanksinya, aparat penegaknya siapa dan sanksi yang jelas." (Inf 1)

"Untuk pengawasannya sampai saat ini belum ada, jadi cuman pasang spanduk udah gitu aja, untuk petugasnya turun kelapangan belum ada, saran bagi petugas lain untuk kedepannya dibuat lagi cara sosialisasi yang kreatif, inovatif, agar masyarakat
}

yang awam itu lebih tertarik menerapkan kebijakan Kawasan Tanpa Rokok dan petugasnya memonitoring langsung kelapangan untuk mengecek masyarakat maupun petugas yang merokok di Kawasan Tanpa Rokok kemudian diberikan sanksi atau denda, sehingga ada efek jera".'( Inf2-Inf 8)

Hasil obervasi diperoleh belum ada dilakukan pengawasan terhadap pelanggaran kebijakan, baik dari instansi terkait maupun dari pihak stakeholder. Sedangkan hasil penelusuran dokumen di dapatkan bahwa Dinas Kesehatan membentuk komite kelompok kerja untuk melaksanakan Perda nomor 5 tahun 2016 tentang kawasan tanpa rokok dan saat ini pelaksanaannya hanya berdasarkan Perda tersebut.

Hasil triangulasi tentang birokrasi pelaksananaan kebijakan kawasan tanpa rokok berdasarkan Perda nomor 5 tahun 2016 di kawasan Dinas Kesehatan Kabupaten Indragiri Hilir diperoleh hasil belum ada komite pengawasan di Dinkes Kabupaten Inhil.

\section{Pembahasan}

Sumber daya merupakan salah satu faktor penting dalam implementasi kebijakan (Winarno, 2012). Perintah-perintah implementasi mungkin diteruskan secara cermat dan konsisten, tetapi jika para pelaksana kekurangan sumber-sumber yang diperlukan untuk melaksanakan kebijakan-kebijakan, maka implementasi ini pun akan cenderung tidak efektif.

Fasilitas fisik termasuk hal yang penting bagi keberhasilan implementasi kebijakan oleh para implementator. Fasilitas fisik sebagai saran dan prasarana pendukung diperlukan untuk memperlancar proses komunikasi kebijakan. Tanpa fasilitas fisik yang memadai, implementasi juga tidak akan efektif. Fasilitas fisik ini beragam bergantung pada kebutuhan kebijakan. Pernyataan tersebut didukung oleh penelitian Siregar (2015) yang menyimpulkan bahwa masih rendahnya informasi dan himbauan tentang KTR pada pegawai dan pengunjung rumah sakit dr.Pringadi Medan menyebabkan pelaksanaan implementasi belum dilaksanakan secara maksimal.

Pendapat peneliti terkait sumber daya pada implementasi kebijakan KTR di kawasan Dinas Kesehatan Kabupaten Indragiri Hilir adalah masih kurangnya fasilitas sarana pendukung dalam pelaksanaan KTR, seperti belum ada rambu-rambu area khusus merokok, mana batasan-batasan daerah bebas asap rokok dan mana tempat yang diperbolehkan untuk merokok, dan belum ada tempat khusus untuk merokok sehingga peneapan KTR belum terlaksana dengan baik.

Komunikasi memiliki peran/fungsi yang cukup penting untuk menentukan keberhasilan kebijakan publik dalam implementasinya. Salah satu kelemahan dalam proses kebijakan publik ini, khususnya yang terjadi di Indonesia adalah masalah implementasinya. Salah satu faktornya adalah komunikasi yang lemah. 
Kelemahan komunikasi ini sebenarnya tidak hanya terjadi pada saat implementasinya, tetapi juga pada saat formulasi. Implementasi yang efektif selain membutuhkan komunikasi yang jelas, juga membutuhkan komunikasi yang konsisten (Anggara, 2014).

Pendapat peneliti, komunikasi yang dilakukan belum berjalan dengan baik kepada pelaksana kebijakan sehingga sosialisasi tidak berjalan maksimal. Sebaiknya Dinkes Kabupaten Inhil melakukan himbauan secara langsung pada saat pegawai Dinas Kesehatan melakukan apel pagi, berhubung dalam kondisi pandemic covid 19 Dinas Kesehatan dapat menempel stiker di tempat/ruangan yang menjadi larangan merokok.

Dalam implementasi kebijakan, jika ingin berhasil secara efektif dan efisien, para implementator tidak hanya harus mengetahui apa yang harus mereka lakukan, tetapi juga mempunyai kemauan untuk mengimplementasi kebijakan tersebut. Jika para pelaksana kebijakan baik terhadap suatu kebijakan tertentu, dan hal ini berarti adanya dukungan, kemungkinan besar mereka akan melaksanakan kebijakan sebagaimana yang diinginkan oleh para pembuat keputusan awal.

Menurut Anggara, 2014 pemahaman terhadap tujuan kebijakan sangat penting bagi aparat pelaksana. Apabila sistem nilai yang memengaruhi sikapnya berbeda dengan sistem nilai pembuat kebijakan, implementasi kebijakan tidak akan berjalan efektif. Pernyataan tersebut didukung oleh penelitian Azhka (2013) yang menyimpulkan bahwa KTR tanpa adanya komitmen dan dukungan dari semua pihak sulit untuk penerapan KTR. Di samping Kawasan Tanpa Rokok (KTR) dapat memberikan perlindungan kepada perokok pasif sekaligus KTR juga mungkin dapat menurunkan perokok aktif.

Adapun pendapat peneliti, Kepala Dinas Kesehatan sebagai pimpinan pelaksana kebijakan, perlu membuat SK/SPT tentang kejelasan tugas dan tanggung jawab dari penerapan kebijakan tersebut baik pelaksana monitoring dan penegakan terhadap sanksi pelanggaran, agar jelas tugas dan fungsi masing-masing. Dengan kejelasan tersebut penerapan KTR di kawasan Dinkes dapat berjalan dengan maksimal.

Struktur birokrasi Edwards III adalah mekasnisme kerja yang dibentuk untuk mengelola pelaksanaan sebuah kebijakan. Meskipun sumber-sumber untuk mengimplementasikan suatu kebijakan sudah mencukupi dan para implementor telah mengetahui apa dan bagaimana cara melakukannya, serta mereka mempunyai keinginan untuk melakukannya, implementasi kebijakan bisa jadi masih belum efektif, karena terdapat ketidakefisienan struktur birokrasi yang ada.

Hasil penelitian Siregar (2015) menyimpulkan bahwa kurang efektifnya pengawasan mengakibatkan masyarakat cenderung terbiasa merokok dilingkungan rumah sakit hal tersebut dikarenakan petugas maupun pegawai yang termasuk dalam tim satgas anti rokok lengah dalam melakukan pengawasan serta di pengaruhi lingkungan RSUD dr. Pirngadi Medan sangat luas dan besar lingkungannya sehingga sulit menjangkau sudutsudut yang menjadi tempat pelarian para perokok untuk mencari aman menghndari petugas rumah sakit.

Adapun pendapat peneliti, Dinkes belum membentuk komite pengawasan penerapan KTR, Dengan tidak adanya komite pengawasan menjadikan pengunjung dan pegawai berani untuk melanggar kebijakan di lingkungan Dinkes. Seharusnya Dinkes membentuk komite melalui kasubag kepegawaian untuk melibatkan security sebagai pengawas dalam penerapan KTR. Hal ini dapat di sahkan dalam bentuk SK/ SPT sehingga dapat memantau setiap pelanggaran yang dilakukan, dan implementasi kebijakan KTR dapat berjalan dengan efektif.

\section{SIMPULAN}

Kesimpulan yang didapatkan tentang implementasi Peraturan Daerah Kabupaten Indragiri Hilir Nomor 5 Tahun 2016 tentang Kawasan Tanpa Rokok bahwa implementasi belum berjalan dengan efektif dengan hasil belum ada fasilitas sarana dan prasarana pendukung seperti tempat/ ruangan khusus untuk merokok, bentuk komunikasi yang dilakukan tidak berjalan dengan maksimal, belum ada struktur organisasi tentang kejelasan tugas dan tanggung jawab pelaksana monitoring dan kebijakan terhadap sanksi pelanggaran dan belum ada komite pengawas yang memantau setiap pelanggaran yang dilakukan.

Disarankan kepada Dinkes Kabupaten Indragiri Hilir agar dapat membuat tempat duduk (pojok) khusus merokok di luar pagar area Dinas Kesehatan, dan diberi kejelasan dengan rambu-rambu mana batasan yang boleh merokok dan mana yang tidak diperbolehkan merokok, melakukan himbauan secara langsung pada saat pegawai Dinas Kesehatan melakukan apel pagi, membuat struktur organisasi dan di sahkan dalam bentuk SK/SPT kepada beberapa pegawai sebagai penanggung jawab dalam pelaksanaan KTR dan membuat komite pengawas dan di sahkan dalam bentuk SK/SPT kepada security sebagai pengawas dalam penerapan KTR yang memantau setiap pelanggaran.

\section{DAFTAR PUSTAKA}

Azkha, N. (2013). Studi Efektifitas Penerapan Kebijakan Perda tentang Kawasan Tanpa Rokok (KTR) dalam Upaya Menurunkan Perokok Aktif di Sumatera Barat Tahun 2013. Jurnal Kebijakan Kesehatan Indonesia. Vol. 2, No.4, Desember 2013.

Anggara, Sahya. (2014). Kebijakan Publik. Bandung: CV Pustaka Setia

Kemenkes RI. (2013). Peraturan Menteri Kesehatan Republik Indonesia Nomor 65 Tahun 2013 
Perawati, Nopriadi, Novita Riany, Kiswanto dan Tin Gustina, Analisis Implementasi Kebijakan Kawasan Tanpa Rokok Berdasarkan Perda Nomor 5 Tahun 2016 Di Dinas Kesehatan Kabupaten Indragiri Hilir

Tentang Pedoman Pelaksanaan Dan Pembinaan Pemberdayaan Masyarakat Bidang Kesehatan.

Peraturan Daerah Kabupaten Indragiri Hilir Nomor 5 Tahun 2016 tentang Kawasan Tanpa Rokok

Riset Kesehatan Dasar. (2013). Badan Penelitian dan Pengembangan Kesehatan Kementrian Kesehatan RI. Retrieved from www.depkes.go.id/resources/download/general/H asil Riskesdas 2013.pdf

Riset Kesehatan Dasar. (2018). Badan Penelitian dan Pengembangan Kesehatan Kementerian RI tahun 2018. Retrieved from https://kesmas.kemkes.go.id/assets/upload/dir_519 d41d8cd98f00/files/Hasil-riskesdas2018_1274.pdf

Siregar, Erra Putri. (2015). Analisis Implementasi Kebijakan Kawasan Tanpa Rokok (KTR) di RSUD dr. Pirngadi Medan Tahun 2015. Tesis FKM. USU Medan

TCSC, 2012. Kawasan Tanpa Rokok dan Implementasinya. Policy Paper Seri 4. Jakarta: TCSC.

Undang-Undang Republik Indonesia Nomor 36 Tahun 2009 tentang Kesehatan

Winarno. (2012). Kebijakan Publik: Teori dan Proses. Edisi Revisi. Jakarta: Media Pressindo 